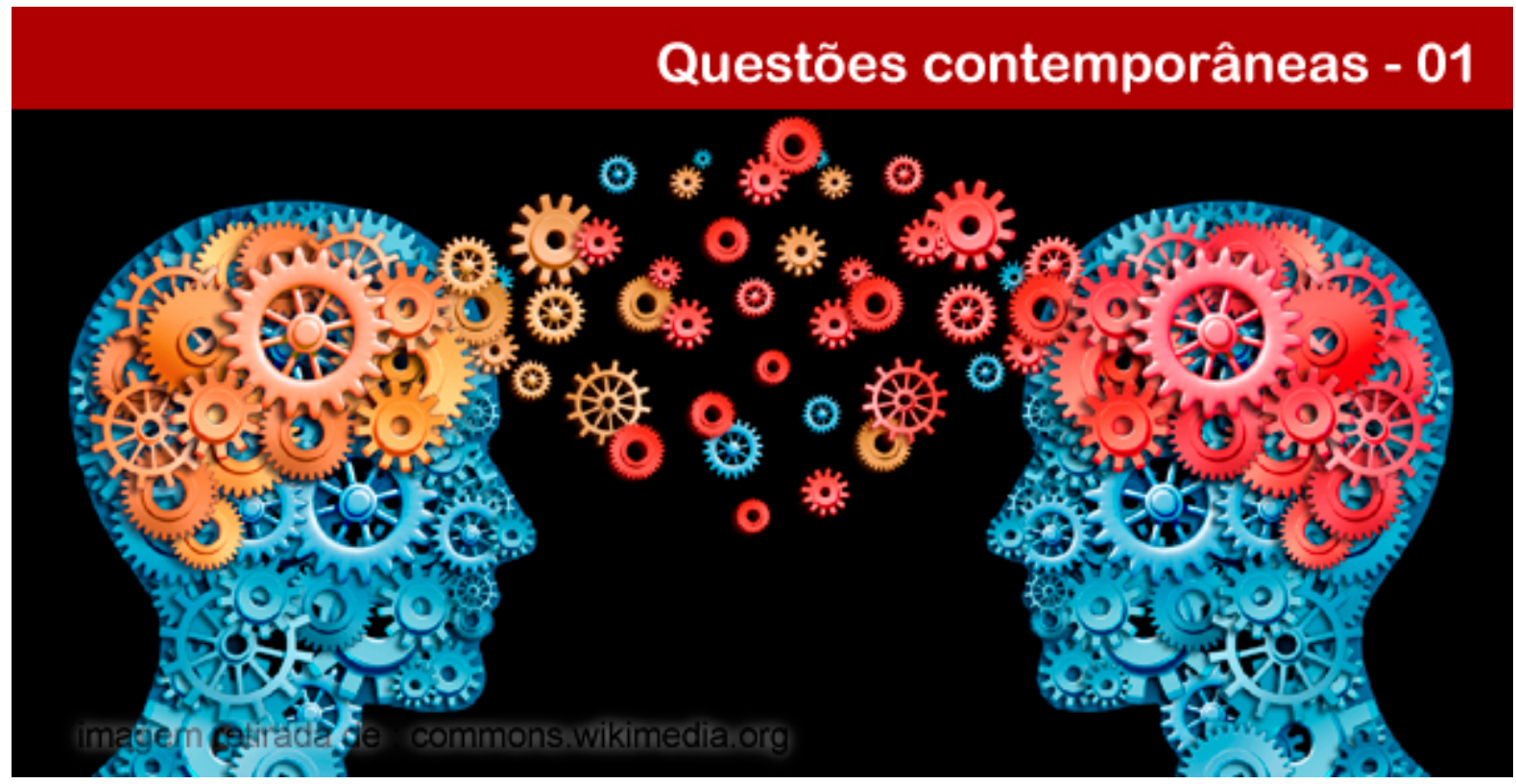

\title{
PSICOLOGIA NÃO SE ESCREVE COM S: UM RESGATE À CIÊNCIA PSICOLÓGICA
}

\section{Luis Anunciação}

Doutorando em Psicologia pela Pontifícia Universidade Católica do Rio de Janeiro (PUC-RJ). Mestre em Saúde Coletiva pela Universidade do Estado do Rio de Janeiro (2012). Graduado em Psicologia pelo Instituto Brasileiro de Medicina de Reabilitação (2008).E-mail: luisfca@gmail.com.

Resumo: Este artigo é um estudo conceitual, de natureza qualitativa, que pretende narrar e descrever as definições de Psicologia em face de alguns de seus aspectos teóricos e operacionais. Partindo do cenário atual onde existem considerações díspares tanto sobre o conceito de ciência psicológica, como à definição do comportamento humano, trilha-se quatro caminhos diferentes visando à solução desta condição: a academia, a bibliografia, o mercado e a Neuropsicologia. Em seguida, a Neuropsicologia é apresentada como forma para resolver esta situação polissêmica. Finalmente, faz-se a defesa de que o critério que deva ser utilizado para considerar se determinada área do conhecimento, ou se uma disciplina, é integrante da ciência psicológica recai sobre seu estatuto de evidências e não sobre seu apelo retórico ou imagético. Acredita-se que este trabalho sirva para fomentar não só o pensamento crítico, mas também a ação efetiva sobre uma Psicologia que se escorou demais visando problematizar tanto sua atividade, como as congêneres, mas se esqueceu de resolver seus impasses fundamentais.

Palavras-chave: Psicologia. Ciência. Formação profissional.

\section{PSYCHOLOGY IS NOT PSYCHOLOGIES: RESCUING PSYCHOLOGY}

Abstract: This conceptual study aims to narrate and describe the definitions of psychology facing theoretical and operational aspects. Based on the current scenario where there are disparate considerations on the concept of psychological science and the definition of human behavior, this paper will address to solve this condition regarding four different ways: academia, literature, free market and Neuropsychology. Then, Neuropsychology is presented as a way to resolve this ambiguous situation. Finally, this study claims that the criterion that should be used to evaluate if a particular area of knowledge, or a discipline, is part of psychological science lies in evidences, but never in rhetorical or imagery appeal. This work fosters not only the critical thinking, but also effective actions on the psychology.

Keywords: Psychology. Science. Professional qualification.

\section{POLÊM!CA $\mid$ LABORE (3:}

Polêmica - Revista Eletrônica da Uerj - Rua São Francisco Xavier, 524, $1^{\circ}$ andar bloco D, sl.1001 • Tels.: +55 21 2334-4088 / 4087 • http://www.e-publicacoes.uerj.br/index.php/polemica/index http://www.labore.uerj.br • laboreuerj@yahoo.com.br 
Definições para Psicologia não faltam e a análise desta tarefa costuma chegar a uma mesma lógica: Psicologia é a ciência do comportamento, mente e cérebro (GAZZANIGA, HEATHERTON, 2005). Esta definição enxuta guarda dois termos que fizeram com que houvesse a clara separação desta área com a Filosofia e que o objeto da Psicologia fosse escolhido. O primeiro termo, ciência, solicitou às pesquisas em Psicologia a utilização de métodos e técnicas de comum acordo científico, e está aí a importância que existe no estudo de disciplinas como métodos científicos, estatística e matemática para construção do conhecimento psicológico. O segundo, formado pela tríade comportamento, cérebro e mente, forma a estrutura sobre a qual essas pesquisas serão aplicadas. Esta definição será o critério de referência no decorrer do presente texto, que adota uma postura monista sobre o mérito.

Naturalmente, o impacto gerado por uma disciplina cuja missão é o estudo do comportamento (humano), além de atravessar diversos outros campos de conhecimento, serve para costurar relacionamentos até então bastante distantes. Como exemplo desta relação de atravessamento, a administração pôde se beneficiar das descobertas que a Psicologia traçou sobre a motivação humana para assegurar melhor conceitos como qualidade de vida no trabalho e benefícios por desempenho (ROONEY, HIGGINS, SHAH, 1995); a economia foi extremamente ajudada pelas descobertas sobre como o pensamento humano ocorre, quais são os critérios normalmente utilizados para tomada de decisão e como o julgamento costuma sofrer interferência de vieses cognitivos (LEA, TARPY, WEBLEY, 1987); o marketing viu nas leis da Gestalt, promulgadas por Wertheimer Köhler e Koffka principalmente, um repertório quase infinito para melhorar estratégias de divulgação e propaganda (CLEMENTE, 2002), entre outros.

Avançando nesta análise, se algumas disciplinas se beneficiaram pelos conhecimentos produzidos pelos psicólogos, a própria Psicologia foi dando o nutriente para alinhavar campos cuja estrutura não se coadunava de forma correlata. Dois exemplos podem ser expressos na área da educação: apesar do pouco contato desta disciplina com a biologia, os estudos da Psicologia e da psicobiologia geraram estratégias de ensino às crianças. Hoje, há evidências de que é mais produtivo ensinar matemática após uma sessão de música, já que o cérebro identifica os elementos musicais como ritmo, tempo e melodia de forma análoga à espacialidade, sequência e correspondência (GEIST, GEIST, KUZNIK, 2012). Em outra direção, a psicometria moderna, ao unir modelos de regressão estatística na confecção de

\section{POLÊM!CA $\mid$ LABORE}

Polêmica - Revista Eletrônica da Uerj - Rua São Francisco Xavier, 524, $1^{\circ}$ andar bloco D, sl.1001 • Tels.: +55 21 2334-4088 / 4087 • http://www.e-publicacoes.uerj.br/index.php/polemica/index http://www.labore.uerj.br • laboreuerj@yahoo.com.br 
testes psicológicos, permitiu construir um formato totalmente inovador de avaliação acadêmica para o vestibular, que é o Exame Nacional do Ensino Médio, o ENEM (INSTITUTO NACIONAL DE ESTUDOS E PESQUISAS EDUCACIONAIS ANÍSIO TEIXEIRA, 2011).

Em torno desta situação, sabe-se que, de forma geral, uma ciência contribui para aquisição de novos conhecimentos em outras áreas, mas que também é responsiva às novas informações advindas de campos diferentes. Assim, se anteriormente se expressou a contribuição dada pelos cientistas psicólogos em outros campos, a própria Psicologia é tributária de conhecimentos congêneres, como é o caso da teoria da evolução e da etologia (ATKINSON et al., 2002; GAZZANIGA, HEATHERTON, 2005).

Porém, se a aplicação de alguns conhecimentos obtidos pela ciência psicológica parece revelar o sucesso desta disciplina e que também existe uma reciprocidade informacional, nem tudo é tão exitoso como se espera. O meio interno da Psicologia funciona aos moldes de uma torre de babel desde a data que marca a consolidação da Psicologia como Ciência, oficialmente chancelada no ano de 1879 (LAGACHE, 1949). Em outras palavras, não obstante o marco histórico daquilo que se chama de "ciência psicológica”, mais de 100 anos se passaram e os debatedores do tema ainda não parecem terem chegado a um acordo nem sobre o objeto de estudo desta ciência, tampouco sobre o método pertinente para seu estudo (ILARDI, FELDMAN, 2001). Apesar de grande reconhecimento que o objeto da Psicologia é o comportamento (CABRAL, NICK, 2006), conforme aqui igualmente entendido, diversas correntes e escolas de pensamento apresentam definições variadas para este objeto. Além disso, a definição que se oferece de ciência também parece plástica, sendo possível encontrar autores que defendem que determinada linha de pesquisa ou de influência em Psicologia é calcada na ciência, enquanto outros não concordam em nada com isso (BEREITER, 1994). Um exemplo desta situação está no caso específico da psicanálise, uma das áreas de maior influência na Psicologia: uns dirão que a psicanálise é uma ciência e outros dirão que é pseudociência (CONN, 1980). Ainda gravita nesta situação a aplicação polivalente acadêmica, onde haverá disciplinas que para alguns autores devem ser incluídas como Psicologia e outros autores dirão que não devem constar desta inclusão. Novamente, o caso da psicanálise pode ser utilizado aqui: se alguns autores defenderão a distinção entre psicanálise e Psicologia, enquanto outros dirão que na verdade ela é a real Psicologia (FINE, 1986).

\section{POLÊM!CA $\mid$ LABORE}

Polêmica - Revista Eletrônica da Uerj - Rua São Francisco Xavier, 524, $1^{\circ}$ andar bloco D, sl.1001 • Tels.: +55 21 2334-4088 / 4087 • http://www.e-publicacoes.uerj.br/index.php/polemica/index http://www.labore.uerj.br • laboreuerj@yahoo.com.br 
Parece que se chegou a um ponto onde a Psicologia só consegue ser definida por situação operacional ou, pior ainda, por critério tautológico. Em outras palavras, tal como o gato de Schrödinger, pode-se operacionalmente definir Psicologia como (qualquer) área que estude de uma forma (que se diga) científica o (que esta forma entenda por) comportamento humano, ou que: Psicologia é simplesmente tudo aquilo que não é Psicologia. Certamente, mesmo que se reconheça que esta situação é insana, ela não é insensata e as fontes de resolução deste fenômeno se encontram em colisão. O aprofundamento desta situação em áreas da Psicologia mostra uma catástrofe ainda maior, como é visto em Pasquali (2007), que, ao citar os tipos de validades que um instrumento possui, literalmente solicita que "você está convidado a acrescentar outros tipos de validade, se quiser utilizar sua criatividade ou sobrar espaço!” (p. 100), pois também acredita que nesta área o rumo foi perdido.

Neste trabalho, visa-se responder a uma pergunta muito clara, que é feita nos seguintes moldes: se existem tantas considerações díspares tanto sobre o conceito de ciência psicológica, como a relacionada à definição do comportamento humano, qual é a que deve ser utilizada? Em outras palavras, em um mundo praticamente ilimitado de possibilidades argumentativas sobre o mesmo fenômeno, qual se mostra a com maior arcabouço de evidências científicas? Certamente, a motivação deste trabalho não é problematizar a área, outrossim, auxiliar a resolver este impasse.

Aqui, apresentar-se-á quatro possíveis estratégias para resolver esta situação, mas se posicionará em uma. As estratégias descritas serão: 1. a acadêmica, 2. a bibliográfica (os livros e artigos), 3. o mercado e 4. a Neuropsicologia. Como será observado, a todo tempo, o critério de narrativa será em associação às práticas baseadas em evidências e pela utilização de técnicas lógicas descritas no balooney kit, de Carl Sagan. Deixa-se claro que o método de pesquisa é o analítico-conceitual, uma proposta de análise qualitativa.

Frisa-se que a eleição de vernáculos na escrita deste trabalho é proposital e feita visando à parcimônia explicativa e que a exploração do campo é referenciada bibliograficamente aos moldes de um ensaio. Os temas colaterais surgidos no processo de elaboração ideacional serão discorridos em momento posterior.

\section{A academia}

As faculdades de Psicologia estão circunscritas em algumas esferas jurídicoadministrativas. As peças legislativas do Ministério da Educação (MEC) devem ser

\section{POLÊM!CA $\mid$ LABORE}

Polêmica - Revista Eletrônica da Uerj - Rua São Francisco Xavier, 524, $1^{\circ}$ andar bloco D, sl.1001 • Tels.: +55 21 2334-4088/4087 • http://www.e-publicacoes.uerj.br/index.php/polemica/index http://www.labore.uerj.br • laboreuerj@yahoo.com.br 
respeitadas; existe a autonomia institucional para decidir sobre ênfase acadêmica, critério de avaliação de alunos, entre outras e, finalmente, o curso deve ser reconhecido pelo MEC e se manter dentro dos critérios do Exame Nacional do Ensino Médio, ENADE, para celebrar sua continuidade.

Frente às peças legislativas, em 2007, o Ministério da Educação expediu a Resolução $\mathrm{n}^{0}$. 2, que norteia sobre carga horária mínima e procedimentos relativos à integralização educação dos cursos de graduação, bacharelados, na modalidade presencial (MINISTÉRIO DA EDUCAÇÃO, 2007). Acredita-se serem importantes dois pontos deste documento, que são: 1. o parágrafo único do Art. $1^{\circ}$ e 2 o anexo, onde o curso de Psicologia tem sua carga horária mínima decidida.

Enquanto o parágrafo único decide que apenas 20\% da carga horária pode ser preenchida por estágio e atividades complementares nos cursos presenciais, o anexo dispõe que um aluno de Psicologia deve ter 4.000 horas de aulas. Esta determinação é a mesma para o curso de odontologia e ambos só estão abaixo da faculdade de medicina, que pede 7.200 horas mínimas para sua conclusão.

No quadro legislativo do Ministério da Educação, também há a resolução $n^{0} .5$ de 2011, que institui as diretrizes curriculares nacionais para os cursos de graduação em Psicologia, estabelecendo normas para o projeto pedagógico complementar para a formação de Professores de Psicologia (MINISTÉRIO DA EDUCAÇÃO, 2011), assinada pelo psicólogo Dr. Paulo Speller, psicólogo formado pela Universidad Veracruzana, no México.

Esta peça legislativa expõe os princípios e os fundamentos para o curso e, entre elas, cita-se que, nas palavras do autor, “a formação de um psicólogo deva ser comprometida com a construção e desenvolvimento do conhecimento científico em Psicologia” (Art. $3^{\circ}$ ) e com a formação de um profissional que tenha competência "de avaliar, sistematizar e decidir as condutas mais adequadas, baseadas em evidências científicas” (Art. $4^{\circ}$ ), apoiada na habilidade "de utilizar os recursos da matemática, da estatística e da informática para a análise e apresentação de dados e para a preparação das atividades profissionais” (Art. 9º). Evidentemente, há outras diretrizes descritas na Resolução e a avaliação da mesma deve ser fundamental a todo leitor deste trabalho para que não haja o viés publicitário (REIDER, 2013).

Ainda na esfera legislativa, os cursos de Psicologia são frequentemente avaliados pelo ENADE, que é regido pela Portaria Normativa ${ }^{\circ} 40$ de 2007 e tem as normas para o que é

\section{POLÊM!CA $\mid$ LABORE}

Polêmica - Revista Eletrônica da Uerj - Rua São Francisco Xavier, 524, $1^{\circ}$ andar bloco D, sl.1001 • Tels.: +55 21 2334-4088/4087 • http://www.e-publicacoes.uerj.br/index.php/polemica/index http://www.labore.uerj.br • laboreuerj@yahoo.com.br 
esperado ao alunado na Portaria Instituto Nacional de Estudos e Pesquisas Educacionais Anísio Teixeira (INEP) no 243. Esta última peça legal diz que o estudante será avaliado para que se possa medir se ele consegue "I - avaliar, sistematizar e decidir as condutas profissionais, com base em evidências científicas”, bem como se consegue "V - utilizar os recursos da matemática, da estatística e da informática para a análise e apresentação de dados e para a preparação das atividades profissionais”.

Finalmente, uma vez que é impossível descrever e analisar os projetos pedagógicos, optou-se por buscar, dentre sete universidades que dispõem do curso de Psicologia e que foram submetidas ao ENADE em 2012, matérias cuja natureza se endereçam ou aproximam ao pedido legislativo. As faculdades consultadas foram: Centro universitário Celso Lisboa, Centro Universitário Hermínio da Silveira (IBMR), Pontifícia Universidade Católica do Rio de Janeiro, Universidade do Estado do Rio de Janeiro, Universidade Estácio de Sá, Universidade Federal do Rio de Janeiro e Universidade Veiga de Almeida. Ressalva-se que a Universidade Gama Filho foi descredenciada em 2014 pelo SERES n ${ }^{\circ} .2$ e por isso não foi incluída na lista. Além disso, não foi possível localizar a grade curricular da UVA. Acreditase que essa inconsistência foi ocasionada por problemas externos às faculdades.

Especificamente na UERJ, não há matéria intitulada "Estatística”. Porém, há a disciplina de nome "Pesquisa quantitativa em Psicologia”, cuja emenda é exatamente esta: "Demonstrar a importância da pesquisa quantitativa nas diferentes etapas para a pesquisa em Psicologia” e não há indicativo de livro texto ou algo similar (UERJ, 2016). Já na UFRJ, disciplinas de natureza quantitativa contemplam mais períodos e são apresentadas como técnicas de Medidas em Psicologia. Psicometria é obrigatória apenas na Celso Lisboa.

As disciplinas biológicas estão descritas separadamente na UFRJ, enquanto as outras Instituições de Ensino Superior (IES), as listam como tópicos de Neurociência. Novamente, na UERJ foi possível constatar duas disciplinas de ênfase biológica, Neuroanatomia e Fisiologia, lecionadas no terceiro e no quarto período respectivamente.

Disciplinas cuja estrutura se aproxima ao pensamento científico são nominalmente difíceis de encontrar, mas há correlatos em todas. Psicofarmacologia faz parte da grade obrigatória no Centro universitário Celso Lisboa e no IBMR.

Em outro sentido, algumas disciplinas oferecidas obrigatoriamente parecem se distanciar do que é solicitado legislativamente, como o caso de "Sociedade contemporânea e subjetividade” (UERJ), “Metapsicologia Freudiana” (PUC-Rio), “Desafios Contemporâneos”

\section{POLÊM!CA $\mid$ LABORE}

Polêmica - Revista Eletrônica da Uerj - Rua São Francisco Xavier, 524, $1^{\circ}$ andar bloco D, sl.1001 • Tels.: +55 21 2334-4088 / 4087 • http://www.e-publicacoes.uerj.br/index.php/polemica/index http://www.labore.uerj.br • laboreuerj@yahoo.com.br 
(IBMR), “General English” (Centro Universitário Celso Lisboa) e "Políticas públicas” (UERJ). Ainda, as instituições solicitam que parte da carga horária seja formada em disciplinas não-obrigatórias e, entre elas, é possível identificar "Saúde Vocal do Professor”, “Utopia e modernidade” e “Escola pública imaginária”, todas da UERJ.

Resgatando a motivação deste trabalho, as IES contribuem para a formação plural do alunado. Em palavras diferentes, elas contribuem para a torre de babel descrita anteriormente. Vê-se que o comportamento é estudado por linguagens muito distanciadas, como é o caso da metafísica freudiana e da Psicologia cognitiva e comportamental. Certamente, ambas as disciplinas apresentam suas justificativas históricas, mas as evidências a favor da cientificidade da psicanálise são menores do que as da Psicologia comportamental (POULSEN et al., 2014), o que suscita outra questão que, propositadamente não será contemplada aqui, que é: estaria o psicólogo preparado para tratar casos em saúde mental a partir de uma formação tão híbrida como esta?

Desta forma, acredita-se que é improvável que se consiga capacitar alunos à ciência psicológica com uma carga horária ínfima de disciplinas que são necessárias à elaboração de evidências, como epistemologia, técnicas de pesquisa, estatística e psicometria. Se, por outro lado, o cabo de força tender mais à esfera profissional do que ao desenvolvimento de novos cientistas, pode-se argumentar que todas as instituições pesquisadas arquitetaram matérias voltadas ao estágio profissional, o que novamente geraria a indagação feita anteriormente.

Finalmente, tudo aponta para que a academia sirva muito bem para a pluralidade, mas não consegue se posicionar robustamente diante da lógica que a ciência psicológica estuda o comportamento humano, uma vez que a ciência é definida de uma forma às 8:00 da manhã e de outra totalmente diferente às 3:00 da tarde. Pesa, ainda, sobre esta situação a deselegância acadêmica que gravita entre os docentes que evitam a crítica aos colegas sempre que possível. Desta forma, quem está certo se ninguém está errado?

\section{A bibliografia}

Magistralmente, ninguém irá se opor ao conteúdo de livros e artigos em periódicos científicos. Cada qual com sua particularidade, ambas as fontes apresentam características que a tornam válidas em relação à consulta acadêmica. Em Psicologia, os livro-texto são frequentemente introduzidos aos acadêmicos no primeiro ano de curso e são eleitos pelos

\section{POLÊM!CA $\mid$ LABORE}

Polêmica - Revista Eletrônica da Uerj - Rua São Francisco Xavier, 524, $1^{\circ}$ andar bloco D, sl.1001 • Tels.: +55 21 2334-4088 / 4087 • http://www.e-publicacoes.uerj.br/index.php/polemica/index http://www.labore.uerj.br • laboreuerj@yahoo.com.br 
docentes visando à exposição da maior parte do conteúdo que o aluno irá ver durante a graduação.

Como exemplo de livros de autores internacionais, há os de Michael Gazzaniga, Rita Atkinson, David Myers e Linda Davidoff. Também há os livros introdutórios à Psicologia escritos por autores brasileiros, como os de Ana Bock, Odair Furtado e Maria de Lourdes Trassi Texeira e o livro de Luiz Cláudio Figueiredo e Pedro Luiz Ribeiro Santi.

Independente do estilo de escrita e repertório de conteúdo que cada obra apresenta, seria um engano acreditar que a questão traçada neste artigo estaria encerrada e que além da definição precisa, o objeto e os métodos seriam igualmente representados. Na verdade, o que ocorre nos livros é justamente a fotografia mais clara desta torre de babel (e provavelmente, uma das variáveis causais dela). Mesmo que, conforme dito logo ao início, haja consenso de que a Psicologia se dirige ao estudo do comportamento, essa posição se distancia entre os autores.

Por exemplo, se a Psicologia é definida como “o estudo científico do comportamento e dos processos mentais" (ATKINSON et al., 2002, p. 25) ou como o "estudo da mente, do cérebro e do comportamento” (GAZZANIGA, HEATHERTON, 2005, p. 40). Figueiredo (1998) prefere “por enquanto, não estabelecer nenhuma conclusão” (p. 17) e Bock, Furtado e Teixeira (2001) não definem o termo, mas citam que a “mente é como o pára-quedas: melhor aberto" (p. 26).

À luz dos antigos jogos de tabuleiro, o autor deste trabalho defende que esta contestação nos faz voltar algumas casas e concluir que Psicologia é tudo aquilo que não é Psicologia ou imaginar a colisão (ou o monólogo a dois), que seria o diálogo entre um psicólogo brasileiro e outro americano.

Não sem razão, poderia se argumentar que os livros não acompanham a evolução do campo de pesquisa por razões óbvias. Desta forma, uma saída em busca da resolução desta panacéia seria a constante atualização acadêmica via leitura de artigos de periódicos científicos. Essa é uma saída com raras chances de sobrevida, uma vez que aguardar que uma pessoa dispenda todo seu tempo em atualização acadêmica assemelha-se ao chamado "evento impossível” em matemática. Pesa sobre esta condição a reflexão: se 38\% dos estudantes de nível superior não são plenamente alfabetizados (INAF, 2011), quantos terão alguma habilidade, ou até mesmo uma simples desenvoltura, em ler artigos em língua outra que o Português? Um otimismo frente ao número só é possível quando comparativo com outros,

\section{POLÊM!CA $\mid$ LABORE}


principalmente ao que evidencia que apenas $8 \%$ das pessoas em idade de trabalhar podem ser consideradas plenamente capazes de entender e se expressar por meio de letras e números (INAF, 2015).

Ainda neste sentido, infere-se que se as referências de livro-texto apresentam também essa querela, com alguma probabilidade, a atualização acadêmica via artigos poderia justamente servir para prejudicar ainda mais o que se espera de um cientista calcado em evidências. Certamente, existem ressalvas claras e sensatas, mas não se vê como metrificar quais são os periódicos (brasileiros) isentos desta miscelânea sem fugir do escopo deste artigo e também ponderar sobre os critérios de classificação já realizados atualmente pela CAPES. Não longe do assunto, ainda há a questão dos chamados “periódicos predatórios”, que não pautam na qualidade do texto a sua avaliação, mas no valor pago pelos autores (BERGER, CIRASELLA, 2015).

Novamente, as definições de “comportamento” e “ciência” não foram resolvidas pela saída bibliográfica. Na verdade, salvo ressalvas, esta saída se mostra como ainda mais perigosa para a Psicologia e para o psicólogo, já que nem sempre existem revisões às cegas e o conteúdo destes jornais são apelos autoritários (porém, pagos) à crença em suas afirmativas, como expõe Berger e Cirasella (2015).

\section{O mercado}

Defende-se aqui que falar de mercado pode ser mentalmente visualizado como convidar alguém a visitar dois locais diferentes: uma feira popular e uma biblioteca. Se a feira popular mostra o que se entende por mercado em ação, a biblioteca elenca os teóricos que se colocam para explicar esta dinâmica. Alerta-se que quaisquer possibilidades de falar sobre os preceitos da economia neste trabalho serão encerradas precocemente pela seleção conveniente de alguns autores que serão privilegiados em face da motivação deste trabalho.

Em outras palavras, o recorte econômico que é feito neste artigo serve para se correlacionar à narrativa, mas não para servir como local privilegiado de estudo. Afinal, o presente artigo visa à pergunta: se existem tantas considerações díspares tanto sobre o conceito de ciência psicológica, como a relacionadas à definição do comportamento humano, qual é a que deva ser utilizada?

Posto isto, sabe-se que tanto na feira popular, como na biblioteca, seja para comprar uma fruta, seja para adquirir um livro, sem dinheiro isso não é possível. Nada é de graça e isto

\section{POLÊM!CA $\mid$ LABORE}

Polêmica - Revista Eletrônica da Uerj - Rua São Francisco Xavier, 524, $1^{\circ}$ andar bloco D, sl.1001 • Tels.: +55 21 2334-4088 / 4087 • http://www.e-publicacoes.uerj.br/index.php/polemica/index http://www.labore.uerj.br • laboreuerj@yahoo.com.br 
foi fielmente representado por Milton Friedman em sua célebre frase "não existe almoço grátis” (FRIEDMAN, 1975). Poderia se complementar esta lógica arguindo que até o desperdício de comida é pago e que, na maioria dos mercados, os consumidores conhecem o preço dos produtos e serviços e tentam alcançar a maior qualidade pelo menor custo, despertando assim uma disputa entre os agentes econômicos e fazendo a maquinária do custo de oportunidade funcionar (RICE, RICE, WEDIG, 2015).

A Psicologia e os serviços psicológicos são produtos de consumo enquadrados na categoria de serviços. Saúde não é mercadoria, mas é um ótimo negócio! O adoecimento (ou mesmo o receio de adoecer) é uma indústria milionária que pode ser descrita em números americanos formados por siglas confusas relacionadas à escolha do plano de saúde. Por exemplo: o HMO é o plano mais básico e significa health maintence organization e dá direito apenas a um médico clínico geral; mas se o cliente quiser algo além, pode optar pelo PPO, que irá permitir consultas com especialistas da rede coberta pelo plano (chamado de in network). Se o consumidor preferir algo independente de regulamentação governamental, ainda há as opções do HealthCare.org, por exemplo. No fim das contas, a saúde movimenta aproximadamente 3 trilhões de dólares por ano, mesmo em anos de pouco crescimento econômico (MARTIN et al., 2012)

Os serviços em Psicologia não funcionam no vácuo econômico. Eles se dão nesta engenharia mercadológica que auxilia na precificação, na elaboração dos custos e na aferição das receitas, que são pilares administrativos e econômicos básicos (FRANK, BERNANKE, 2009). Apesar de não haver ninguém que discorde que a graduação de Psicologia oferece pouquíssimo conteúdo voltado à gestão, acredita-se, aqui, que a vida profissional do psicólogo comece exatamente no momento em que ele pensa como atrair clientes ao seu serviço. Mesmo que este hiato entre academia e mercado ocorra, o cotidiano pedirá que algumas competências administrativas e econômicas sejam desenvolvidas.

Retornando ao conceito econômico que apregoa que o consumidor irá maximizar a qualidade tentando reduzir o preço, ou o psicólogo equaliza o valor de seu serviço ou terá uma sobrevida ameaçada pela concorrência. Desta forma, mesmo que sem nomear perfeitamente, a lei da demanda e da oferta e as lógicas de elasticidade de preço que precisam de um ingrediente-chave para funcionar: concorrência. Assim, fica claro que o mercado deva ser sempre considerado também como uma fonte de consulta bastante eficiente para qualquer

\section{POLÊM!CA $\mid$ LABORE}

Polêmica - Revista Eletrônica da Uerj - Rua São Francisco Xavier, 524, $1^{\circ}$ andar bloco D, sl.1001 • Tels.: +55 21 2334-4088 / 4087 • http://www.e-publicacoes.uerj.br/index.php/polemica/index http://www.labore.uerj.br • laboreuerj@yahoo.com.br 
disciplina acadêmica: se algo está no mercado e resiste ao tempo e aos concorrentes, uma das variáveis causais desta permanência é a eficácia do produto.

A lista de concorrentes não precisa ser longa para que se perceba os diferentes posicionamentos que os psicólogos tendem a fazer nesta disputa. De um lado, há os concorrentes de mesmo nível, que são outros psicólogos oferecendo seus serviços; de outro lado, há os concorrentes externos, que são os não-psicólogos oferecendo serviços que atuam exatamente no mesmo objeto. Ainda há nesta esfera os concorrentes que não ofertam serviços, mas sim produtos, como as caixas orgônicas e os aparelhos de reprogramação de pensamento. É importante frisar que não raro será possível vislumbrar que os serviços oferecidos pelos psicólogos e os oferecidos pelos outros concorrentes não funcionam sob categorias estanques, mas sim sob uma curva de gradação: o coach e o psicólogo cognitivo-comportamental, por exemplo, poderão ter estratégias extremamente parecidas para resolver uma situação psicológica, mesmo que a nomeiem por titulações radicalmente diferentes. Ainda nesta situação, os produtos também podem ser combinados aos serviços, como no caso do psicólogo que faz atendimento clínico, mas também se utiliza de uma caixa orgônica quando julga necessário.

Apesar do mercado não ter compromisso com a ciência, sabe-se que a ciência se tornou um valor nas sociedades contemporâneas (GIBBONS et al., 1994, p. 133) e desempenha um papel importante nas interações do mercado: de um lado há os cientistas criando e adequando descobertas - meio que sem saber se elas têm valor comercial, e de outro há os agentes comerciais que têm interesse no desenvolvimento de produtos lucrativos, mas que não estão bem inteirados do que os cientistas têm feito (HELLMANN, 2007).

A Psicologia funciona dentro desta estrutura e também disponibiliza seus produtos aos consumidores. Porém, não é conhecida uma metodologia específica que auxilie ou norteie a busca de produtos que são desenvolvidos sob égide da Psicologia. Desta forma, constata-se que o mercado tem alto viés de confirmação associado a um leque quase infinito de produtos, já que pode apresentar diferentes soluções que não possuem interesse em responder à pergunta: “o que é ciência” ou “o que é comportamento”, mas justamente ir para o lado oposto, complicando ainda mais esta dinâmica.

No entanto, é justamente nesta quantidade quase ilimitada de possibilidades que começa a se ver uma saída possível quando se percebe a ascensão e rápida expansão de projetos como o lumosity e o cogmed, que movimentam cifras milionárias e visam o

\section{POLÊM!CA $\mid$ LABORE}

Polêmica - Revista Eletrônica da Uerj - Rua São Francisco Xavier, 524, $1^{\circ}$ andar bloco D, sl.1001 • Tels.: +55 21 2334-4088 / 4087 • http://www.e-publicacoes.uerj.br/index.php/polemica/index http://www.labore.uerj.br • laboreuerj@yahoo.com.br 
treinamento do cérebro. Não obstante a ainda falta de evidências robustas sobre a efetividade destas atividades de treinamento cognitivo (OWEN et al., 2010; UNSWORTH et al., 2015), a alavanca desses projetos não está na Psicologia no geral, mas especificamente no cérebro, que é o órgão eleito pelos programas.

Novamente, o mercado não aponta a solução para a polissemia, mas sim a eleva ao quadrado, com algum risco de tornar a Psicologia em apenas folk psychology. No entanto, vêse com desvelo o crescimento que ocorre nas tecnologias voltadas ao aprimoramento do cérebro.

\section{A Neuropsicologia}

A década de 1950 deflagrou uma espécie de anos dourados à Psicologia. George Miller, Noam Chomsky, Alan Newell, Herbert Simon e Ulric Neisser, entre outros, “enterraram” o Behaviorismo que reinava nos Estados Unidos com novas explicações sobre a inteligência, linguagem, memória e percepção humana. Em suma, é nesta época que a Psicologia resgata a ponte com a Europa, revisita as teorias e descobertas dos gestaltistas e abre uma espécie de porta às outras áreas, como a ciência computacional, a linguística, para semear o que hoje chamamos de neurociência (MILLER, 2003).

Aqui, considera-se que a aproximação com outras ciências resultou em um avanço para a Psicologia. Desta vez, o acúmulo de possíveis descrições e explicações oferecidas aos objetos da ciência psicológica eram naturalmente discutidos por profissionais com diferentes formas de pensar e desenvolver teoria, mas que endereçavam o cérebro como local que representa e interpreta as informações do ambiente para nele testar suas hipóteses de pesquisa. Outros 4 eixos nortearam a Psicologia cognitiva: 1. Eventos mentais têm correspondência ponto a ponto com eventos cerebrais, 2. Todos os eventos mentais ocorrem como resultado do processamento neural, 3. Os comportamentos não voluntários também ocorrem como resultado do processamento neural e 4. Os genes são determinantes importantes do padrão de interconexão entre neurônios e cérebro, bem como aos detalhes de seu funcionamento (ILARDI; FELDMAN, 2001)

Passo a passo, esses autores foram endereçando suas descobertas à área cognitiva, que foi sendo consolidada como uma ciência específica, a ciência cognitiva (GALOTTI, 2015, p. 11) e em um caminho que foi subsidiando a Neuropsicologia. Desta forma, enquanto a Psicologia cognitiva se ocupava das relações entre funções cerebrais e cognições, a

\section{POLÊM!CA $\mid$ LABORE}

Polêmica - Revista Eletrônica da Uerj - Rua São Francisco Xavier, 524, $1^{\circ}$ andar bloco D, sl.1001 • Tels.: +55 21 2334-4088 / 4087 • http://www.e-publicacoes.uerj.br/index.php/polemica/index http://www.labore.uerj.br • laboreuerj@yahoo.com.br 
Neuropsicologia especificamente via como as lesões cerebrais se associavam às cognições. Ambas as áreas apresentam sobreposições, o que é esperado, uma vez que seu objeto de comportamento é similar: o cérebro (GROOME, 2014, p. 12-15).

O que a Neuropsicologia evidencia é a resposta mais precisa para a definição de comportamento humano e de ciência. Para estudar o comportamento humano, deve-se estudar o cérebro e a ciência funciona a partir do paradigma moderno, com testagem de hipóteses a partir de ferramentas estatísticas.

\section{Considerações finais}

Finalmente, defendeu-se aqui um posicionamento à definição de Psicologia, bem como o critério para excluir desta disciplina aquilo que não é compatível. Argumenta-se que a Psicologia é a ciência que estuda o comportamento humano e que qualquer teoria que não tenha acumulado tanto evidências para sua sustentação, como critérios que permitam pesquisas de replicação, devam ser endereçadas à Psicologia como parte de sua história ou como leque de influências. As disciplinas que se dizem Psicologia, mas que não utilizam como método de pesquisa o estatístico, neste artigo, são vistas como Filosofia. Não perdem seu valor, mas não podem ser vistas como científicas.

Evidentemente, sabe-se que a ciência se apresenta dinamicamente e suas descobertas são derivadas do passar do tempo, do aprimoramento instrumental, de paradigmas de medida e da sofisticação teórica, entre outras. Tendo em vista isto, a saída oferecida para as possíveis situações onde haja lacunas explicativas reside em definir a ciência não apenas em seus resultados, mas sim na forma de pensar orientado por dois pilares fundamentais: ceticismo e lógica estatística.

Neste sentido, acredita-se que o que se entenda por Psicologia é, na verdade, Neuropsicologia, uma vez que esta resolveu os problemas expostos previamente relacionados à pluralidade de definições, teorias e autores dispersos sobre a definição da Psicologia. Em outras palavras, a Psicologia não funciona no vácuo. Desta maneira, quando o presente artigo adota que Psicologia é Neuropsicologia, ele visa desfazer qualquer polissemia em relação às práticas que são feitas como se fossem Psicologia, mas que não fornecem evidências de seu funcionamento.

Na ponta da lança, um psicólogo é, de fato, um neuropsicólogo, cuja definição de Psicologia recai muito mais em como a variável cérebro irá atuar criando a mente e se

\section{POLÊM!CA $\mid$ LABORE}

Polêmica - Revista Eletrônica da Uerj - Rua São Francisco Xavier, 524, $1^{\circ}$ andar bloco D, sl.1001 • Tels.: +55 21 2334-4088 / 4087 • http://www.e-publicacoes.uerj.br/index.php/polemica/index http://www.labore.uerj.br • laboreuerj@yahoo.com.br 
comportando, do que como essas estruturas geram o cérebro. Em noção de causalidade, um Neuropsicólogo não inverte causa e efeito.

\section{POLÊM!CA $\mid$ LABORE}




\section{Referências}

ATKINSON, R. L. et al. Introdução à Psicologia de Hilgard. Porto Alegre: Artmed, 2002.

BEREITER, C. Implications of postmodernism for science, or, science as progressive discourse. Educational Psychologist, v. 29, n. 1, 1994. DOI: 10.1207/s15326985ep2901_1.

BERGER M.; CIRASELLA, J., Beyond Beall’s List: Better understanding predatory publishers. College \& Research Libraries News, 132-135, 2015. doi:http://crln.acrl.org/content/76/3/132.full.pdf+html.

BOCK, A. M. B.; FURTADO, O.; TEIXEIRA, M. D. L. T. Psicologias: uma introdução ao estudo de Psicologia. São Paulo: Saraiva, 2001.

CABRAL, Á.; NICK, E. Dicionário técnico de Psicologia. São Paulo: Cultrix, 2006.

CLEMENTE, M. N. The Marketing Glossary: Key Terms, Concepts and Applications. New Jersey: Clemente Organization Group, 2002.

CONN, J. H. Is psychoanalysis alive and well at 85? A rejoinder. The Pavlovian journal of biological science, v. 15, n. 3, July 1980. 131-134. DOI: 10.1007/BF03003694.

FIGUEIREDO, L. C. M. Psicologia, uma (nova) introdução: uma visão histórica da Psicologia como ciência. São Paulo: EDUC, 1998.

FINE, R. PSYCHOANALYSIS AND PSYCHOLOGY. Psychological Reports, 1986. 695-708. DOI: doi: 10.2466/pr0.1986.59.2.695.

FRANK, R. H.; BERNANKE, B. S. Principles of Economics + Economy 2009 Update. New York: The McGraw-Hill Companies, 2009.

FRIEDMAN, M. There's no such thing as a free lunch. Open Court: [s.n.], 1975.

GALOTTI, K. M. Cognitive Psychology: In and Out of the Laboratory. Los Angeles: SAGE, 2015.

GAZZANigA, M. S.; HEATHERTON, T. F. Ciência Psicológica. Mente, cérebro e comportamento. Porto Alegre: Artmed, 2005.

GEIST, K.; GEIST, E. A.; KUZNIK, K. The Patterns of Music: Young Children Learning Mathematics through Beat, Rhythm, and Melody. Young Children, 2012. 74-79.

GIBBONS , M. et al. The new production of kowledge: the dinamics of science and research in contemporary societes. Los Angeles : SAGE, 1994.

GROOME, D. An Introduction to Cognitive Psychology: Processes and Disorders. New York: Psychology Press, 2014.

HELLMANN, T. The role of patents for bridging the science to market gap. Journal of Economic Behavior \& Organization, v. 63, n. 4, 2007. 624-647.

ILARDI, S. S.; FELDMAN, D. The cognitive neuroscience paradigm: A unifying metatheoretical framework for the science and practice of clinical psychology. Journal of Clinical Psychology, 2001.

INAF. Indicador de Analfabetismo Funcional: principais resultados. INAF Brasil 2011. São Paulo. 2011.

INAF. Alfabetismo no Mundo do Trabalho. São Paulo, 2015.

\section{POLÊM!CA $\mid$ LABORE}

Polêmica - Revista Eletrônica da Uerj - Rua São Francisco Xavier, 524, $1^{\circ}$ andar bloco D, sl.1001 • Tels.: +55 21 2334-4088 / 4087 • http://www.e-publicacoes.uerj.br/index.php/polemica/index http://www.labore.uerj.br • laboreuerj@yahoo.com.br 
INSTITUTO NACIONAL DE ESTUDOS E PESQUISAS EDUCACIONAIS ANÍSIO TEIXEIRA. Nota técnica. Assunto: Teoria de Resposta ao Item. [S.l.]. 2011. Disponível em http://download.inep.gov.br/educacao_basica/enem/nota_tecnica/2011/nota_tecnica_tri_enem_18012012.pdf.

LAGACHE, D. L'unite de la Psychologie. Paris: PUF, 1949.

LEA, S. E. G.; TARPY, R. M.; WEBLEY, P. The individual in the economy: A textbook of economic psychology. New york: Cambridge University Press, 1987.

MARTIN, A. B. et al. Growth In US Health Spending Remained Slow In 2010; Health Share Of Gross Domestic Product Was Unchanged From 2009. Health Aff, v. 31, n. 1, p. 208-219, January 2012. DOI: 10.1377/hlthaff.2011.1135.

MILLER, G. A. The cognitive revolution: a historical perspective. TRENDS in Cognitive Sciences, v. 7, n. 3, 2003. 141-144.

MINISTÉRIO DA EDUCAÇÃO. Resolução nº 2, de 18 de junho de 2007, 2007.

MINISTÉRIO DA EDUCAÇÃO. Resolução nº 5, de 15 de março de 2011, 2011.

OWEN, A. M. et al. Putting brain to test. Nature, v. 465, n. 7299, 2010. 775-778. doi: 10.1038/nature09042.

PASQUALI, L. Validade dos Testes Psicológicos: Será Possível Reencontrar o Caminho? Psicologia: Teoria e Pesquisa, v. 23, n. especial, 2007. 099-107.

POULSEN, S. et al. A randomized controlled trial of psychoanalytic psychotherapy or cognitive-behavioral therapy for bulimia nervosa. Am J Psychiatry, 2014. 109-116.

REIDER, B. Publicity Bias. Am J Sports Med, 41, n. 2, February 2013. 261-262. DOI: 10.1177/0363546512475130.

RICE, S. D.; RICE, M. J.; WEDIG, G. Is Our US Health Care System Actually a Market-Based Economy? Anesthesia \& Analgesia, v. 121, n. 4, p. 1114-1115, October 2015. DOI: 10.1213/ANE.0000000000000829.

ROONEY, C. J. R.; HIGGINS, E. T.; SHAH, J. Goals and Framing: How Outcome Focus Influences Motivation and Emotion. Pers Soc Psychol Bull, v. 21, n. 11, November 1995. 1151-1160. doi: 10.1177/01461672952111003.

UERJ. Fluxograma do Departamento de Psicologia, 2015. Disponível em:< http://www.dep.uerj.br/arqs/fluxogamas_cursos/psicologia_bacharelado_e_profissional.pdf/>. Acesso em: 13 de mar. 2016.

UNSWORTH, N. et al. Is Playing Video Games Related to Cognitive Abilities? Psychological Science OnlineFirst, 2015. 1-16. doi: 10.1177/0956797615570367.

Recebido em: 27/12/2015.

Aceito em: 05/04/2016.

\section{POLÊM!CA $\mid$ LABORE}

Polêmica - Revista Eletrônica da Uerj - Rua São Francisco Xavier, 524, $1^{\circ}$ andar bloco D, sl.1001 • Tels.: +55 21 2334-4088 / 4087 • http://www.e-publicacoes.uerj.br/index.php/polemica/index http://www.labore.uerj.br • laboreuerj@yahoo.com.br 